\title{
Analysis of gravity and magnetic data along Mahe-Sumdo-Tso Morari
}

\author{
Rambhatla G Sastry*and Md Israil
}

Department of Earth Sciences, I.I.T, Roorkee INDIA

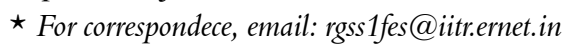

Our gravity and magnetic profile data sampled at $1 \mathrm{~km}$ spacing along Mahe-Sumdo-Tso Morari across Indus-Suture zone to Taglang la formation is analyzed. Gravity data is processed with our variable density Bouguer anomaly computation algorithm. Spectral analysis of gravity and magnetic data indicates that the residual anomaly is of shallow origin. A simple modeling of gravity and magnetic data indicates that the ophiolites has a discordant relationship with ISZ and Taglang la formations. However, the modeled magnetic anomaly could not yield the bottom surface of inclined dyke.

\section{Introduction}

Ophiolites presence near Indo suture zone (ISZ) in Ladakh Himalaya is a well-known fact. The geometry and structure delineation of them at different locations by gravity and magnetic signatures could be of specific geodynamic interest. Here, our closely sampled $(1-2 \mathrm{~km})$ gravity and magnetic data along Mahe bridge - Sumdo - Panamik is analyzed.

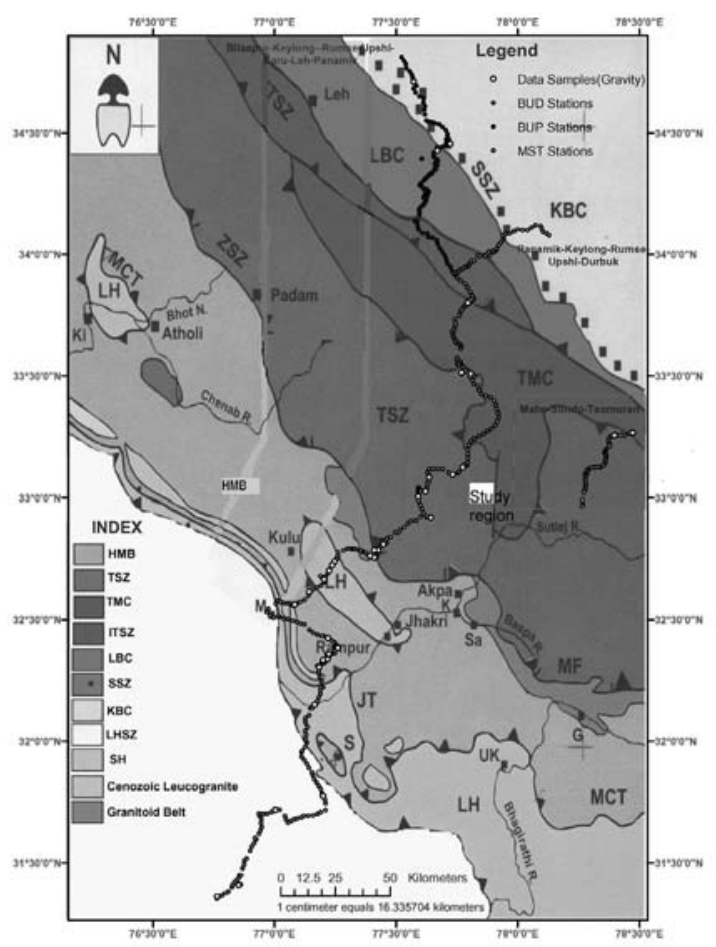

FIGURE 1. Mahe-Sumdo-Tso Morari profile is marked within the box of the above map. Station interval is $1-2 \mathrm{~km}$. Both gravity and magnetic (Total-field intensity) data are acquired along this profile. (After Cover page of Seminar Abstract Volume (Himalayan Tectonics), dated 16-17, 2003, IIT Roorkee)

\section{Methodology}

A regional gravity profile from Ladakh Himalaya along Mahe - Sumdo - Tso-morari (Figure 1) is processed with our algorithm (Sastry 2005) utilizing 'GRAVMASTER' software of 'GEOTOOLS'. Density measurements of collected representative samples from different geological formations along the profile were utilized for this purpose.

The reference Bouguer datum is mean sea level.

The processing of Mahe - Sumdo - Tso Morari profile (Figure 2) is undertaken with two options, viz.,

a) Conventional constant Bouguer density, $\mathrm{D}=2.67 \mathrm{~g} / \mathrm{cc}$ (for both Bouguer and terrain corrections)

b) Variable density for both Bouguer and terrain corrections

The Bouguer anomaly processed with variable density option clearly reflects (Figure 2) the signature of Nidar ophiolites.

Total-field intensity data along the same profile is processed as per norms (Figure 3).

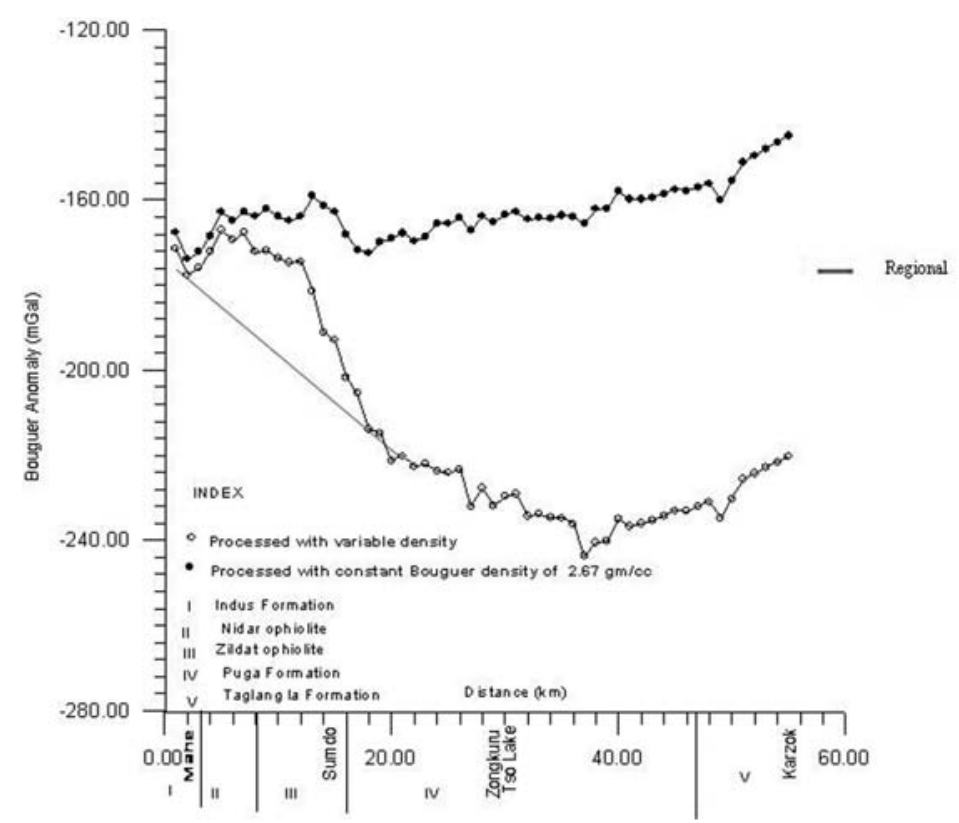

FIGURE 2. Processed Bouguer anomaly along Mahe-Sumdo-Tso Morari Profile with geological formations. For regional-residual separation sake regional is identified by green line in the above plot. A constraint from spectral analysis also supports the above regional trend. 


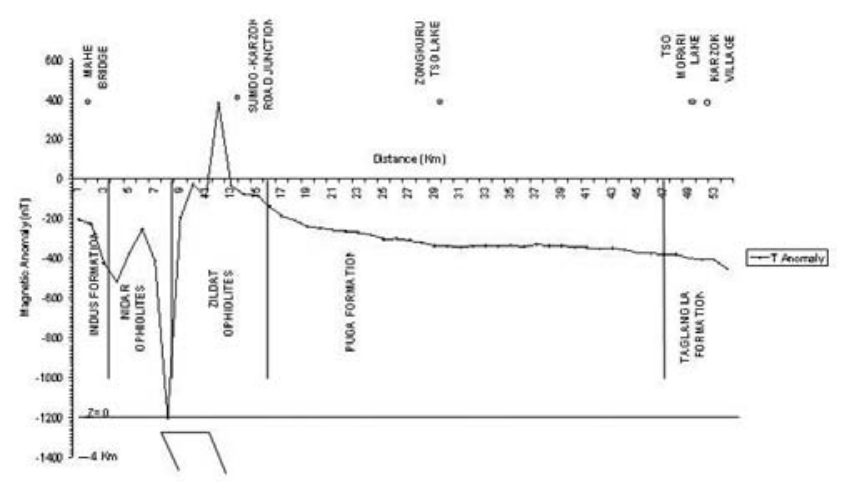

FIGURE 3. Processed magnetic anomaly (Total-field intensity) profile along Mahe-Sumdo-Tso-Morari profile with geological formations. Interpreted dyke model is indicated at the bottom.

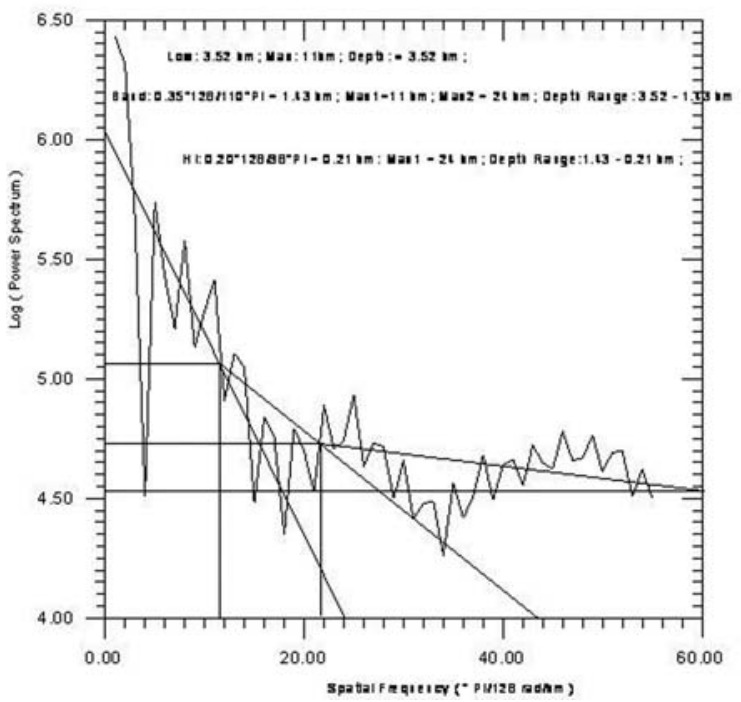

FIGURE 5. Spectral plot for magnetic data along Mahe-SumdoTso-Morari profile. The analysis indicates that residual anomaly source may extend from $0.21-3.5 \mathrm{~km}$. This serves as basis for choice of inclined dyke of infinite-depth extent.

Results and Discussion

Spectral analysis of gravity (Figure 4) and magnetic anomalies (Figure 5) have been carried out as per norms. The inferred source of high-frequency part of the anomalies is approximately 3 $\mathrm{km}$. This has led to quantitative Interpretation of both gravity and magnetic signatures.

By considering both residual gravity and magnetic anomalies, an inclined dyke model is adopted. The residual gravity is modeled with inclined dyke of finite - depth extent (Figure 6). By considering the gravity results, the magnetic anomaly is modeled with a dyke model of infinite-depth extent (Figure 3 ) as magnetic signature is more influenced by shallow features of the source. The results clearly indicate that the ophiolites extend at least up to $3.5 \mathrm{~km}$ from surface.

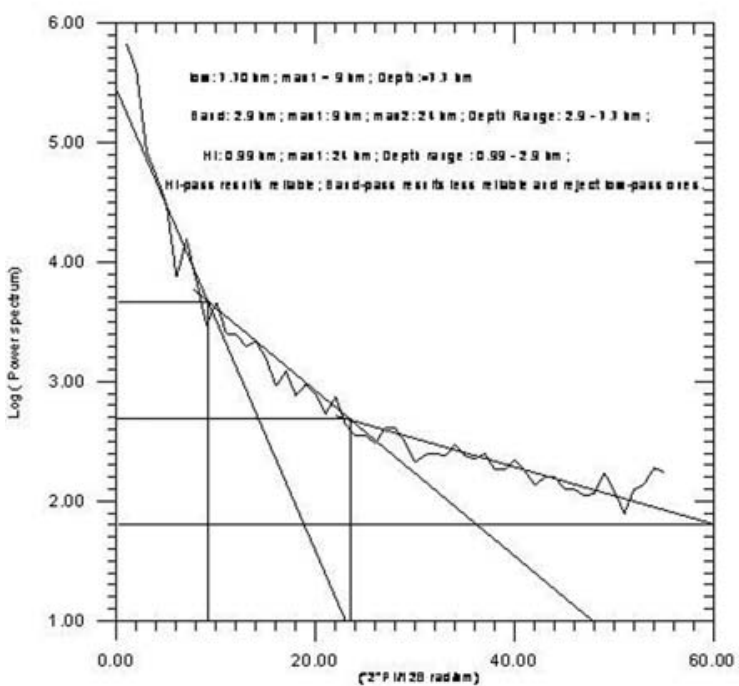

FIGURE 4. Spectral plot for gravity data along Mahe-SumdoTso-Morari profile. The analysis indicates that residual anomaly source may extend from $0.99-3.0 \mathrm{~km}$. This serves as basis for choice of inclined dyke of finite-depth extent.

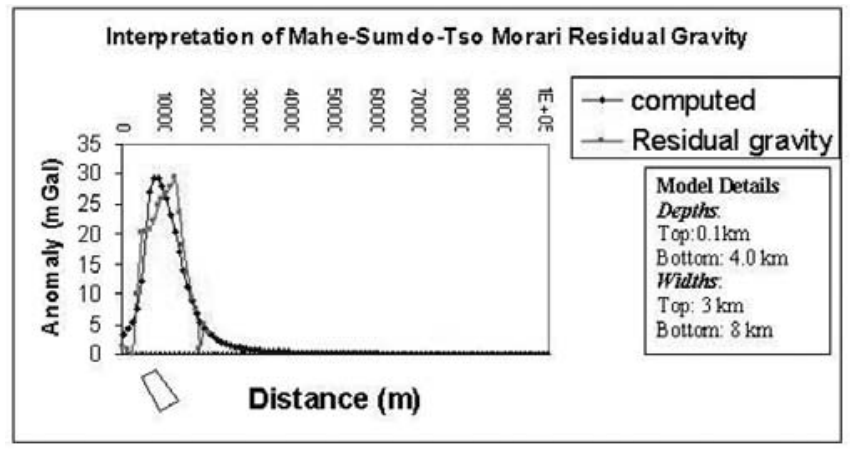

FIGURE 6. Interpreted residual Bouguer gravity along Mahe-Sumdo-TsoMorari profile. Both field and computed profiles are shown. Ophiolites identified by dipping finite-extent dyke serve as source for the residual gravity anomaly. Thus ophiolites have a discordant relationship with Indus and Taglang la formations in this region

Conclusions

The analysis of gravity and magnetic anomalies along MaheSumdo-Tso Morari profile clearly indicates that the ophiolites have a discordant relationship with Indus and Taglang la formations and they extend up to at least $3 \mathrm{~km}$ from surface.

\section{Acknowledgements}

Authors convey their sincere thanks to Sri. DN Awasthi, Chairman, PAMC (DCS), DST, Dr. KR Gupta, Advisor, Dr. Ch. Sivaji, Scientist, DST and all concerned Advisory Committee members of DST "HIMPROBE" team for necessary support and advice. The authors also thank Ms. Neeta Chaudhary, Research Associate for assistance in processing. Thanks are also due to DST, New Delhi for sustained encouragement and support throughout the implementation of the DST project, of which the present piece of work is an outcome. 